\title{
Final-year medical students' ratings of service-learning activities during an integrated primary care block
}

\author{
N Mapukata, ${ }^{1,2}$ MSc (Health Care Management), MSc (Med); M G Mlambo, ${ }^{1,3} \mathrm{PhD} ; \mathbf{R}$ Dube, ${ }^{1} \mathrm{MB}$ BCh \\ ${ }^{1}$ Department of Family Medicine and Primary Care, Faculty of Health Sciences, University of the Witwatersrand, Johannesburg, South Africa \\ ${ }^{2}$ School of Public Health and Family Medicine, Faculty of Health Sciences, University of Cape Town, South Africa \\ ${ }^{3}$ College of Law, Institute for Dispute Resolution in Africa (IDRA), University of South Africa, Pretoria, South Africa
}

Corresponding author: M G Mlambo (motlatso.mlambo@wits.ac.za)

\begin{abstract}
Background. Service learning (SL) has as its pedagogy the ability to link medical education to the community through the identification of healthcare needs for citizens residing in rural and urban underserved communities. Integrated Primary Care (IPC) is a clinical block through which final-year medical students manage common presenting problems in context and engage the community in a reciprocal manner.

Objective. To assess the educational value and enjoyment of the 27 SL activities (SLAs) undertaken by final-year medical students as part of the IPC block. Methods. A cross-sectional descriptive study was conducted among final-year medical students $(N=245)$, focusing on logbook activities during 1 academic year.

Results. Students reported positively on the educational value of the majority of the 17 clinical SLAs, but only 3 activities were ranked the same for enjoyment and educational value. For non-clinical activities, only 2 of 10 were matched for educational and enjoyment value. There was no significant difference in the rating of educational value and enjoyment between rural and urban underserved sites.

Conclusions. The study provided insight into clinical and non-clinical SLAs that accumulate value for students when they are based in primary healthcare settings. The lack of enjoyment on reflective activities is a concern that should be explored through a qualitative review of SLAs.
\end{abstract}

Afr J Health Professions Educ 2019;11(2):35-37. DOI:10.7196/AJHPE.2019.v11i2.906

South Africa (SA), like most other developing countries, has a shortage of doctors, especially in rural and underserved communities, where most of the population's healthcare needs are required. ${ }^{[1]}$ Service learning (SL) is well embedded in the curricula of higher education institutions in SA, as universities must support transformation initiatives and address social ills of the past. ${ }^{[2]} \mathrm{SL}$ as a form of experiential learning is a link between the university and the community. ${ }^{[3]}$ Therefore, a SL curriculum creates an interrelationship between family and community health and different levels of care. ${ }^{[4]}$ Through SL, students are most likely to engage in reflective practice when they encounter real patients with health problems. ${ }^{[5]}$ Furthermore, the decentralised training sites where SL activities (SLAs) are practised offer opportunities for medical students to rekindle their altruistic commitment. ${ }^{[3]}$

Academic SL is a common practice at SA universities. ${ }^{[6]}$ At the University of the Witwatersrand (Wits), Johannesburg, SA, SL is a form of community engagement whereby health science students participate in a range of activities that enhance academic SL and also facilitate purposeful civic engagement. After such exposure, students are required to submit a reflective journal in the form of a portfolio or logbook, where the community attachment includes a clinical component for which students must meet the goals for formative assessment. ${ }^{[7]}$ It is against this background that the Wits Centre for Rural Health introduced the Integrated Primary Care (IPC) block as a 6-week placement for final-year medical students in primary healthcare (PHC) facilities, incorporating reciprocity as a central theme to SL. ${ }^{[7]}$ This study aimed to assess the situated learning experiences of final-year medical students, based on their ratings of the educational value and enjoyment of the 27 SLAs that form part of the IPC block.

\section{Methods}

This descriptive cross-sectional study was conducted among final-year medical students who completed their IPC block in 1 academic year $(N=245)$.

Data were collected at PHC sites where final-year students were placed to gain practical experience of SLAs. The 7 rural sites and 9 underserved urban sites, which were used interchangeably, included clinics, community healthcare centres and level I or II hospitals in rural or urban underserved communities. ${ }^{[7]}$ Data were collected using logbook entries submitted at the end of the 6-week cycle for each of the 7 rotations. The focus of this study was limited to the two sections in the logbook where students were asked to rate the value of an SLA as a learning experience, as well as enjoyment of an SLA. Students rated the SLA values $(1=$ no value and $5=$ great value) and enjoyment $(1=$ no enjoyment and $5=$ great enjoyment $)$ on a 5 -point Likert scale.

Data were captured and analysed descriptively using SPSS Version 25 (IBM Corp., USA). We used cross-tabulations to assess whether being in a rural/urban site led to significant value and enjoyment of an SLA. Associations were considered to be significant at $p<0.05$.

\section{Ethical approval}

Approval for this study was obtained from the Wits Human Research Ethics Committee (ref. no. HREC M1311162) as part of the ongoing evaluation of 


\section{Short Research Report}

the IPC block. The sections that form part of this study were not marked as part of the formative assessment of the student.

\section{Results}

The results are described according to clinical and non-clinical activities. The activities that included less patient contact were classified as non-clinical SLAs, whereas those with more patient contact were classified as clinical SLAs.

\section{Clinical service-learning activities}

Clinical activities that were given the highest educational value were antenatal consultations (91.0\%), undifferentiated patient consultations (91.0\%) and well-baby clinic visits (90.4\%). The same SLAs that rated highly for educational value were also rated highly for enjoyment. These were consultation of well-baby clinics (90.7\%), undifferentiated patients $(83.1 \%)$ and antenatal consultations (82.3\%). A moderate positive and significant correlation between value and enjoyment were found with regard to all clinical SLAs.

\section{Non-clinical service-learning activities}

The role of other health professionals was highly valued (79.0\%) and enjoyed (77.3\%). Interestingly, the school health education (76.7\%) and significant event analysis (68.4\%) were rated equally for both value and enjoyment of SL. Although the health facility audit was valued at $63.5 \%$, it was less enjoyed (43\%). Teleconferences and weekly reflection meetings were less valued and less enjoyed. A moderate positive and significant correlation between value and enjoyment was found regarding all the non-clinical SLAs, except for school health education.

\section{Service-learning value and enjoyment by site}

The comparison of SL value and enjoyment by site is reported in Table 1. In terms of value rating, significant differences were found between urban and rural sites for some SLAs. Only teleconferences $(p=0.021)$ and triage ( $p=0.017$ ) were statistically significant.

In terms of enjoyment rating, significant differences were found between urban and rural sites for some SLAs. Only teleconferences $(p<0.001)$, school health education $(p<0.001)$, observed consultations $(p=0.028)$ and reflective stories $(p=0.047)$ were statistically significant.

\section{Discussion}

This study assessed students' educational value and enjoyment of clinical and non-clinical SLAs. The results revealed the highest rating for both value and enjoyment for the clinical SLAs that involved direct contact with

Table 1. Service-learning value and enjoyment in urban v. rural sites

\begin{tabular}{|c|c|c|c|c|c|c|}
\hline \multirow[b]{2}{*}{ SLA } & \multicolumn{3}{|c|}{ Educational value by site } & \multicolumn{3}{|c|}{ Enjoyment by site } \\
\hline & Urban, \% & Rural, \% & $p$-value & Urban, \% & Rural, \% & $p$-value \\
\hline Antenatal consultations & 92.0 & 88.5 & 0.435 & 82.8 & 80.3 & 0.699 \\
\hline Calls & 87.5 & 85.2 & 0.662 & 69.0 & 69.4 & 1.000 \\
\hline Chronic consultations & 85.0 & 83.1 & 0.683 & 66.1 & 71.2 & 0.523 \\
\hline Consultation of undifferentiated patients & 90.3 & 91.5 & 1.000 & 84.7 & 77.6 & 0.230 \\
\hline Counselling sessions & 82.5 & 90.2 & 0.216 & 67.8 & 70.0 & 0.872 \\
\hline Weekly reflection meetings (NC) & 37.1 & 47.2 & 0.200 & 58.3 & 47.1 & 0.308 \\
\hline Labour ward management & 79.7 & 80.4 & 1.000 & 58.3 & 47.1 & 0.194 \\
\hline Observed consultations & 87.3 & 96.5 & 0.074 & 57.0 & 73.7 & $0.028^{*}$ \\
\hline PMTCT & 84.1 & 80.4 & 0.525 & 66.2 & 62.7 & 0.735 \\
\hline Reflective stories (NC) & 42.4 & 45.8 & 0.640 & 43.0 & 60.4 & $0.047^{\star}$ \\
\hline TB/HIV management & 88.3 & 86.4 & 0.817 & 73.5 & 72.4 & 0.865 \\
\hline Teleconferences (NC) & 38.8 & 56.9 & $0.021^{*}$ & 23.1 & 52.5 & $0.001^{\star *}$ \\
\hline Well-baby clinic activities & 88.7 & 94.9 & 0.164 & 90.4 & 91.2 & 1.000 \\
\hline Anaesthesia & 70.2 & 71.7 & 0.871 & 55.6 & 59.3 & 0.650 \\
\hline Family planning consultations & 75.9 & 72.9 & 0.727 & 71.0 & 69.5 & 0.869 \\
\hline Health facility audit (NC) & 62.2 & 66.1 & 0.641 & 43.2 & 40.7 & 0.762 \\
\hline Home visit (NC) & 74.0 & 78.0 & 0.603 & 73.4 & 72.4 & 0.860 \\
\hline IMCI consultations & 77.8 & 79.3 & 1.000 & 71.3 & 73.7 & 0.865 \\
\hline Medico-legal & 74.8 & 79.7 & 0.593 & 42.6 & 37.9 & 0.641 \\
\hline Mental health patient consultations & 61.2 & 66.7 & 0.534 & 40.2 & 53.3 & 0.095 \\
\hline Mini-CEX & 76.6 & 75.0 & 0.860 & 47.4 & 61.7 & 0.071 \\
\hline Quality improvement project (NC) & 69.0 & 75.9 & 0.404 & 53.2 & 62.1 & 0.285 \\
\hline Referral & 55.5 & 59.6 & 0.643 & 43.9 & 47.4 & 0.757 \\
\hline Role of other health professional (NC) & 78.4 & 80.0 & 0.856 & 77.8 & 76.7 & 0.858 \\
\hline School health education (NC) & 76.7 & 75.9 & 1.000 & 100 & 100 & $0.001^{\star *}$ \\
\hline Significant event analysis (NC) & 67.7 & 69.5 & 0.871 & 40.5 & 33.9 & 0.436 \\
\hline Triage & 52.2 & 75.4 & $0.017^{\star}$ & 46.8 & 56.1 & 0.279 \\
\hline
\end{tabular}


patients, such as antenatal consultation, consultation of undifferentiated patients and well-baby clinic visits. The high rating of SLAs and positive significant correlation regarding both value and enjoyment reflect students' satisfaction with exposure to primary care patients as part of their learning experience. Studies indicate that students tend to accord deep feelings of personal satisfaction and higher educational value to activities where they have direct patient contact. ${ }^{[6,8]}$ In a study by Nyangairi et al. ${ }^{[7]}$ students seemed to enjoy exposure to some common illnesses that they were exposed to during a primary care rotation.

In this study, students seemed to value most of the learning activities if they enjoyed them. This is in accordance with findings reported by Wilson et al., ${ }^{[9]}$ as their students' perceived enjoyment when the activity was considered to be of high value, with the exception of non-clinical activities. In our study, the majority of non-clinical activities were assigned a moderate educational value, except for reflective stories, weekly reflection meetings and teleconferences, which received the lowest ratings. Reasons for these low ratings could be technical problems associated with teleconferencing, such as loss of connection or poor connection during a session. ${ }^{[10]}$ An unexpected finding was the poor ranking of weekly reflections and reflective stories as student-directed non-clinical SLAs. In keeping with a study by Van Hell et al. ${ }^{\left[{ }^{[8]}\right.}$ reflections were not highly valued by our students. Muir ${ }^{[11]}$ attributed this to students requiring much more guidance about how to reflect, and failure to introduce reflective practice earlier in the curriculum.

Overall, students' experiences were not influenced by site allocation either urban based and underserved or rural for the majority of SLAs, except for triage, where students in rural sites seemed to derive more educational value than their urban counterparts. Nyangairi et al. ${ }^{[7]}$ alluded to the PHC context being valued much more than the location of the setting, as students focused on potential attributes, such as providing holistic care to the patient. Our students expressed value and enjoyment of home visits, school health projects and time spent with other healthcare professionals as non-clinical SLAs, which is supported by Leung et al. ${ }^{[4]}$ As one of the benefits of the SL curriculum, they cite exposure to relationships between the community and health facility, as well as different levels of healthcare. The attachment of value to health-promotion activities reported in our study was linked to the opportunity for medical students to engage learners in the choices they make for their future healthcare. ${ }^{[6]}$ Compared with experiences at other universities, where the educational value of SLAs in decentralised training platforms is largely reported from a clinical perspective with either a limited attachment period or limited activities, ${ }^{[9]}$ the 27 SLAs may be too many for students and may also be influenced by the setting.

\section{Conclusions}

This study provided insight into clinical and non-clinical SLAs that accumulate value for students when they are based at PHC settings. Students managed to achieve reciprocal learning through the school health project. They did not enjoy reflecting on their experiences, which is a concern that should be explored through a qualitative review of SLAs.

\section{Declaration. None.}

Acknowledgements. Our gratitude is extended to the research interns who assisted with the data capturing and to Prof. Ian Couper for his input during the conceptual phase of the study.

Author contributions. All three authors were involved in the preparation of the initial draft and also contributed to the final draft.

Funding. None.

Conflicts of interest. None.

1. Couper I, de Villiers M, Sondzaba N. Human resources: District hospitals. In: Ijumba P, Barron P, eds. South African Health Review. Durban: Health Systems Trust, 2005.

Arigher Education Quality Committee South Africa. A Good Practice Guide and Self-evaluation Instruments for Managing the Quality of Service-learning. Pretoria: Council on Higher Education, 2007.

3. Diab P, McNeill PD, Ross AJ. Review of final-year medical students' rural attachment at district hospitals in KwaZulu-Natal: Student perspectives. S Afr Fam Pract 2014;56(1):57-62. https://doi.org/10.1080/20786204.20 14.10844584

Leung K-K, Liu W-J, Wang W-D, Chen C-Y. Factors affecting students' evaluation in a community servicelearning program. Adv Health Sci Educ 2006;12(4):475-490. https://doi.org/10.1007/s10459-006-9019-1

5. Keselyak N, Simmer-Beck M, Bray K, Gadbury-Amyot C. Evaluation of an academic service-learning course on special needs patients for dental hygiene students: A qualitative study. J Dent Educ 2007;71(3):378-379.

6. Srinivas SC, Wrench WW. Evaluation of a service-learning elective as an approach to enhancing the pharmacist's role in health promotion in South Africa. Afr J Health Professions Educ 2012;4(2):107-111. https://doi. org/10.7196/AJHPE.108

7. Nyangairi B, Couper ID, Sondzaba NO. Exposure to primary healthcare for medical students: Experiences of final-year medical students. S Afr Fam Pract 2010;52(5):467-470. https://doi.org/10.1080/20786204.2010.1087 4027

8. Van Hell EA, Kuks JBM, Cohen-Schotanus J. Time spent on clerkship activities by students in relation to their perceptions of learning environment quality. Med Educ 2009;43(7):674-679. https://doi.org/10.1111/j.13652923.2009.03393.x

9. Wilson NW, Bouhuijs PA, Conradie HH, Reuter H, van Heerden BB, Marais BJ. Perceived educational value and enjoyment of a rural clinical rotation for medical students. Rural Remote Health 2008;8(999).

0. Lamba P. Teleconferencing in medical education: A useful tool. Australas Med J 2011;4(8):442-447. https://doi org/10.4066/AMJ.2011.823

1. Muir $\mathrm{F}$. The understanding and experience of students, tutors and educators regarding reflection in medical education: A qualitative study. Int J Med Educ 2010;1:61-67. https://doi.org/10.5116/ijme.4c65.0a0a 